\title{
ИНТЕНСИФИКАЦИЯ ПРОЦЕССА ОБУЧЕНИЯ ПРОФЕССИОНАЛЬНО ОРИЕНТИРОВАННЫМ ИНОЯЗЫЧНЫМ КОММУНИКАТИВНЫМ НАВЫКАМ СРЕДСТВАМИ ОНЛАЙН ТЕХНОЛОГИЙ
}

\author{
Неволина К.В., Подкаменная Е.В., Фетисова С.А.
}

Цель данной работы заключается в систематизации теоретических и практических аспектов проблемы внедрения онлайн технологий в процесс обучения профессионально-ориентированным иноязычным коммуникативным навыкам студентов неязыковых вузов.

Материалы и методы исследования. Применяемый метод анализа и обобщения, а также логический метод позволяют суммировать теоретические наработки в области инновационных направлений преподавания иностранных языков. Базой для практической части исследования являются метод наблюдения и метод эксперимента.

Результаты исследования. Анализ научных работ, посвященных проблеме использования интерактивных форм обучения, послужили отправной точкой для авторской разработки прочедуры обучения организации и проведения вебинаров на английском языке, эффективность которой была доказана экспериментальным путем.

Обсуждение и заключения. Практическая значимость статьи заключается в универсальном характере алгоритма применения вебинара как интерактивной образовательной технологии. Вебинар рассматривается как интерактивная форма, организуемая и проводимая самими студентами для совершенствования навыков их профессионального общения. Результаты проведенного исследования могут быть полезны и интересны как специалистам в области высшего образования и студентам, а также послужить 
материалом для дальнейшего совершенствования инновачиионных форм интерактивного обучения.

Ключевые слова: инновационные методики; онлайн технологии; профессионально ориентированный английский язык; технология обучения вебинарам; обучение в неязыковом вузе.

\section{IMPROVING THE LEARNING OF PROFESSIONAL FOREIGN LANGUAGE COMMUNICATION SKILLS THROUGH ONLINE TECHNOLOGY}

\section{Nevolina K.V., Podkamennaya E.V., Fetisova S.A.}

Purpose. The purpose of the research is to systematize theoretical and practical aspects of implementing online technologies into the process of teaching ESP communication skills to students of non-linguistic universities.

Data and methods of research. The research methodology is based on theoretical and practical methods. The method of analysis and generalization, as well as the logic method are used to summarize theoretical developments in the sphere of innovative approaches to teaching foreign languages. The practical part of the study is based on the methods of observation and experiment.

Results. In the study, the authors present their technology of teaching to organize and conduct webinars in English, based on the analysis of scientific works devoted to interactive forms of teaching. The effectiveness of the technology was experimentally proved.

Contribution and conclusion. Practical relevance of the research shows webinars as a cross functional interactive learning technology where students host the online event developing their professional skills. The results of the study can be valuable for both higher school teachers and students and can be used for further development of innovative forms of interactive learning.

Keywords: innovative methods; online technologies; English for specific purposes; webinar teaching technology; non-linguistic university. 


\section{Введение}

Дистанционные образовательные технологии позволяют акцентировать личностно-ориентированный подход в обучении. Особую актуальность использование интерактивных форм обучения получает при изучении иностранных языков в неязыковых вузах, поскольку традиционные методы не справляются с задачей генерирования интереса к изучению непрофилирующей дисциплины. Как показывает анализ, одной из наиболее продуктивных из имеющихся в арсенале онлайн технологий является вебинар, который отвечает таким требованиям современной системы образования как доступность (географическая, тематическая, количественная), индивидуальный подход, осуществление индивидуальной траектории обучения, а также экономическая рентабельность.

Преимущества вебинара определяют цель данного исследования, заключающейся в решении проблемы внедрения вебинара как онлайн технологии в процесс формирования у студентов навыков, позволяющих интегрироваться в международную профессиональную среду и использовать иностранный язык как средство межкультурного общения.

\section{Обзор литературы}

В последние годы появилось много публикаций, посвященных проблеме интерактивного обучения (Ф. Бенгтсон, Н.Ю. Вильгельм,Т.Л. Герасименко, Е.А Иноземцева, Е.В. Коротаева, Л.И. Кутепова, О.О. Налимова, Л.М. Ображей, М.А. Терентьева, Б. Хеммингс, П. Шмидт, И. Элсеид) [16], [2], [3], [5], [6], [7], [8], [9], [14], [16], [19], [18].

Исследователей сходятся во мнении, что в настоящее время в системе образования приоритетными являются принцип учета интересов обучаемого, развитие коммуникативно-развивающего и социально-ориентационных аспектов обучения, которые в свою очередь актуализируются в интерактивных формах обучения. Задачами данного вида обучения являются повышение интереса студентов к изучаемой дисциплине, приближение учебы к практике повседневной жизни, научение приемам получения социологического знания [4, с. 173]. 
Вебинар находит свое применение как в широком плане, например, как средство достижения воспитательных целей [12]; форма дистанционного обучения [11]; способ проведения различных мероприятий [13]; средство получения образования [1]; а также как средство узкой направленности, например, для изучения иностранного языка.

Следует отметить, что на сегодняшний день вебинар используется в основном как онлайн-канал «передачи» знаний от преподавателя к студентам [2].

\section{Постановка задач, методы и технология обучения}

В целом, анализ существующих исследований обнаружил недостаточную разработанность вопроса использования вебинаров с активным участием студентов на занятиях по иностранному языку в неязыковых вузах, что делает актуальными сформулированные авторами задачи исследования: разработать технологию обучения проведению вебинаров на английском языке и экспериментальным путем проверить эффективность предложенной технологии.

Технология обучения вебинарам включает разработанный авторами комплекс упражнений, состоящий из следующих типов: рецептивные, рецептивно-репродуктивные, репродуктивные, продуктивные. Упражнения распределены по этапам. На ознакомительном этапе используются рецептивные упражнения; этапы анализа и планирования включают в себя рецептивные, рецептивно-репродуктивные, продуктивные упражнения; этап реализации состоит из продуктивных упражнений. Все упражнения в соответствии с этапами подробно описаны в статье «Обучение организации и проведению вебинаров как средство формирования иноязычной профессиональной компетенции» [10].

\section{Описание исследования}

Описанная авторами технология обучения организации и проведению вебинаров была апробирована в ходе экспериментального 
обучения. Эксперимент носил естественный характер и проходил в рамках курса английского языка в профессиональной сфере в течение четырех недель по два часа в неделю. В эксперименте участвовало 25 студентов ГОУ ВПО ИГЛУ и 20 студентов ФГБОУ ВО ИГУ, всего 4 группы, которые были поделены на основе теста предэкспериментального среза на экспериментальную (ЭГ) и контрольную группы (КГ).

Эффективность разработанной технологии оценивается по следующим критериям: уровень владения профессионально-направленным иностранным языком, соответствие правилам проведения вебинара, интерактивное взаимодействие со слушателями, умение отвечать на вопросы подготовленного и спонтанного характера, оформление поствебинарной стадии. На основе данных критериев было выделено три уровня сформированности навыка организации и проведения вебинаров на английском языке: низкий, средний и высокий.

Эксперимент состоял из трех этапов: подготовительный этап, собственно эксперимент, постэкспериментальный этап.

На подготовительном этапе экспериментального обучения было проведено анкетирование студентов с целью выявления уровня знаний о вебинарах, практического опыта участия и мотивации к овладению навыками их организации и проведения в экспериментальной и контрольной группах.

Результаты анкетирования студентов показали, что 90\% из них в целом имеют определенное представление о том, что такое вебинар; при этом только 10\% опрошенных сумели объяснить значимость вебинаров для их профессиональной деятельности; 70\% ограничилось описанием вебинара как вида онлайн обучения; 10\% высказали мнение, что вебинары это способ выманивания денег; 10\% респондентов затруднились с ответом. 100\% опрошенных изъявили желание научиться проводить вебинары на английском языке.

Для отслеживания динамики на этапе эксперимента и постэкспериментальном этапе были проведены два контрольных среза: промежуточный и итоговый. Результаты всех трех срезов представлены на диаграмме (рис. 1). 
Для того чтобы доказать эффективность эксперимента, мы использовали критерий знаков $\mathrm{G}$ для выявления статистически значимой тенденции в смещении значений каждого показателя и Т-критерий Вилкоксона, позволяющий установить выраженность изменений [15]. Результаты расчетов показали, что в КГ произошли статистически значимые изменения лишь по второму критерию, а в ЭГ по всем критериям.

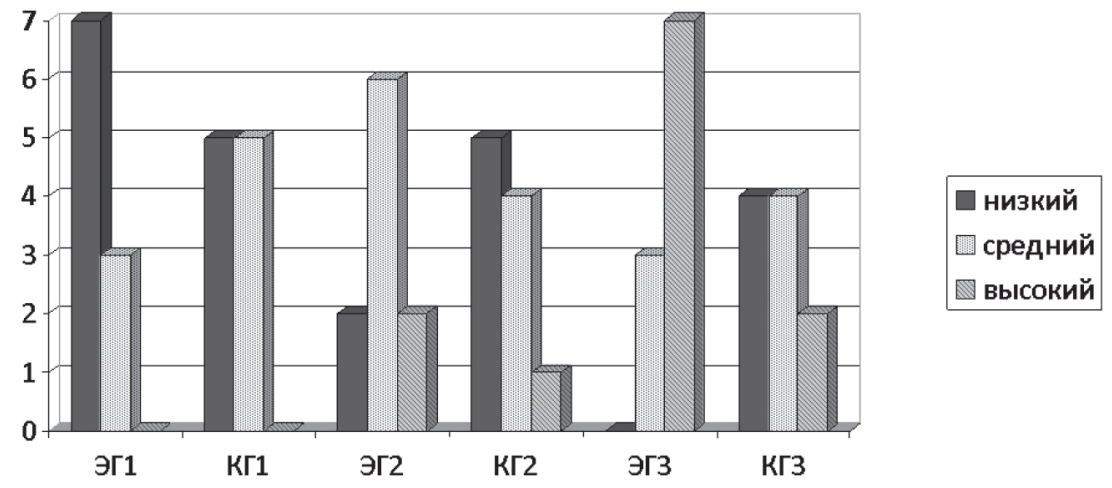

Рис. 1. Динамика уровней сформированности навыков организации и проведения вебинаров по трем срезам (данные эксперимента 2016-2017 уч.г ИГУ)

Экспериментальное обучение доказало эффективность разработанной технологии обучения организации и проведению вебинаров, поскольку все испытуемые в экспериментальной группе показали значительное улучшение результатов. Критерий знаков, критерий Манна-Уитни и Вилкоксона подтвердили исследовательскую гипотезу и доказали эффективность предлагаемой технологии.

\section{Заключение}

Вебинар как инновационная онлайн форма организации учебной деятельности направлен на продуктивное изучение иностранного языка, исключает механическую передачу знаний и вовлекает всех участников образовательного процесса. Ведущая роль студентов в вебинаре развивает способность проявлять инициативу, нести ответственность за собственные решения, порождать новые идеи, по- 
лучать новый опыт, анализировать свои возможности, способствует накоплению и трансляции знания и опыта студентами.

С точки зрения практического внедрения результатов проведенного исследования, разработанная авторами технология обучения вебинарам может быть взята на вооружение как преподавателями, так и студентами направления подготовки Реклама и связи с общественностью и другими специалистами в области высшего образования, а также широкой общественностью.

\section{Список литературы}

1. Вебинар как способ получения образования. [Электронный ресурс]. URL: http://vedaevent.ru/blog1/relizy1/vebinar_kak_sposob_polucheniya_ obrazovaniya-v.html (дата обращения: 30.04.17).

2. Вильгельм Н.Ю. Использование вебинаров при обучении иностранному языку [Электронный ресурc]. URL: http://nsportal.ru/vuz/ filologicheskie-nauki/library/2014/01/12/statya-vebinar-kak-effektivnyyinstrument-pri-izuchenii (дата обращения 16.05.17).

3. Герасименко Т.Л., Грубин И.В., Гулая Т.М., Жидкова О.Н., Романова C.A. Smart-технологии (вебинар и социальные сети) в преподавании иностранного языка в неязыковом вузе // Статистика и Экономика. 2012. № 5. С. 9-12.

4. Добрынина Д.В. Инновационные методы обучения студентов вузов как средство реализации интерактивной модели обучения // Вестник Бурятского государственного университета. 2010. № 5. С. $172-176$.

5. Иноземцева Е.А. Вебинар - современная форма дистанционного обучения // Вестник Московского государственного университета приборостроения и информатики. Серия: Социально-экономические науки. 2012. № 39. С. 145-148.

6. Коротаева Е.В. Интерактивное обучение: вопросы теории и практики обучения // Педагогическое образование в России. 2012. № 2. С. 171-174.

7. Кутепова Л.И., Никишина О.А., Алешугина Е.А., Лошкарева Д.А., Костылев Д.С. Организация самостоятельной работы студентов в 
условиях информационно-образовательной среды вуза // Азимут научных исследований: педагогика и психология. 2016. Т. 5. №3 (16). С. $68-71$.

8. Налимова О.О. Интерактивное обучение как один из вариантов инновационного обучения // Молодой ученый. 2014. №18.1. С. 69-72.

9. Ображей Л.М., Танкаян Н.Г. Интерактивные методы обучения и повышения мотивации студентов к обучению // Инновации в здоровье нации сборник материалов III Всероссийской научно-практической конференции с международным участием. 2015. С. 57-60.

10. Подкаменная Е.В., Фетисова С.А. Обучение организации и проведению вебинаров как средство формирования иноязычной профессиональной компетенции // XI Международная научно-практическая конференция «World Science: Problems and Innovations». Пенза, МЦНС «Наука и просвещение». 2017. С. 261-265.

11. Потапчук О.И. Мобильные информационно-коммуникационные технологии обучения в профессиональной подготовке будущих инженеров-педагогов [Электронный ресурс]. URL: http:/sci-article.ru/ stat.php?i=1436386051 (дата обращения: 01.06.17).

12. Свентицкий Е.И. Вебинары как инновационное средство образования и воспитания активной молодежи // Образование и наука в современных условиях: материалы II междунар. науч.-практ. конф. (Чебоксары, 15 янв. 2015 г). Чебоксары: ЦНС «Интерактив плюс». 2015. С. 221-222.

13. Сидоров С.В. Вебинар как форма дистанционного интерактивного обучения. [Электронный ресурc]. URL: http://si-sv.com/publ/1/ vebinar/14-1-0-351 (дата обращения: 04.06.17).

14. Терентьева М.А. Вебинар - семинар нового поколения в высшей школе // Проблемы и достижения современной науки. 2015. № 1 (2). С. 32-35.

15. Штульман Э.А. Методический эксперимент в системе методов исследования. Воронеж: Изд-во ВГУ, 1971. 144 с.

16. Sharp G., Hemmings B., Russell K., Murphy B., Elliott S. Academic boredom among students in higher education: A mixed-methods explo- 
ration of characteristics, contributors and consequences . Journal of Further and Higher Education. 2016. № 41: 657-677.

17. Bengtsson F., Granmo M. An active partnership: How engaging students as co-producers will change your classroom. The FASEB Journal, 2017. FASEB. URL: http://www.articlesfactory.com/articles/education/ webinar-innovative-applications-of-raptivity-in-education.html (дата обращения: 19.02.18).

18. Elsayed Y. E., La Lopa M. Active and Interactive Teaching Methods: A Study of Their Use in Hospitality Higher Education. Available at: http:// www.academia.edu/27721291/Active_and_Interactive_Teaching_Methods_A_Study_of_Their_Use_in_Hospitality_Higher_Education.

19. Schmidt P., Pittner Ja. Smart off-line webinar for distant education // Открытое образование. 2013. № 5. С. 64-66.

\section{References}

1. Vebinar kak sposob polucheniya obrazovaniya [Webinar as a technique to get education]. Available at: http://vedaevent.ru/blog1/relizy1/vebinar_ kak_sposob_polucheniya_obrazovaniya-v.html (accessed April 30, 2017).

2. Vil'gel'm, N.YU. Ispol'zovanie vebinarov pri obucheni iinostrannomu yazyku [Using webinars in teaching foreign languages]. http://nsportal. ru/vuz/filologicheskie-nauki/library/2014/01/12/statya-vebinar-kak-effektivnyy-instrument-pri-izuchenii (accessed May 16, 2017).

3. Gerasimenko T.L., Grubin I.V., Gulaya T.M., Zhidkova O.N., Romanova S.A. Smart-tekhnologii (vebinarisocial'nyeseti) v prepodavanii inostrannogo yazyka v neyazykovom vuze [Smart-technology in teaching foreign languages in non-linguistic universities]. Statistika i Ekonomika. 2012. № 5: 9-12.

4. Dobrynina D.V. Innovacionnye metody obucheniya studentov vuzov kaksredstvo realizacii interaktivnoj modeli obucheniya [Innovative learning methods in the university level education as a means of implementation of the interactive learning model]. Vestnik Buryatskogo gosudarstvennogo universiteta. 2010. № 5: 172-176.

5. Inozemceva E.A. Vebinar - sovremennaya forma distancionnogo obucheniya [Webinar as a modern format of distance learning]. Vestnik 
Moskovskogo gosudarstvennogo universiteta priborostroeniya i informatiki. Seriya: Sotsial’no-ekonomicheskie nauki. 2012. № 39: 145-148.

6. Korotaeva E.V. Interaktivnoe obuchenie: voprosy teorii i praktiki obucheniya [Interactive learning: theoretical and practical aspects]. Pedagogicheskoe obrazovanie v Rossii. 2012. № 2: 171-174.

7. Kutepova L.I., Nikishina O.A., Aleshugina E.A., Loshkareva D.A., Kostylev D.S. Organizaciya samostoyatel'noj raboty studentov v usloviyah informacionno-obrazovatel'noj sredy vuza [Organising students' selfstudy in information educational environment of the university]. Azimut nauchny issledovanij: pedagogika i psihologiya. 2016. Vol. 5. №3 (16): 68-71.

8. Nalimova O.O. Interaktivnoe obuchenie kak odin iz variantov innovacionnogo obucheniya [Interactive learning as one of the techniques of innovative teaching]. Molodoj uchenyj. 2014. №18.1. pp. 69-72. https:// moluch.ru/archive/77/13248/ (accessed January 15, 2018).

9. Obrazhej L.M., Tankayan N.G. Interaktivnye metody obucheniya i povysheniya motivacii studentov k obucheniyu [Interactive learning methods and ways to encourage students to study]. Innovacii $v$ zdorov'enacii sbornik materialov III Vserossijskoj nauchno-prakticheskoj konferencii s mezhdunarodnym uchastiem [Innovations in the health of the nation a collection of materials of the III All-Russian Scientific and Practical Conference with international participation]. 2015: 57-60.

10. Podkamennaja E.V., Fetisova S.A. Obuchenie organizaciii provedeniju ve-binarov kak sredstvo formirovanija inojazychnoj professional'noj kompetencii [Teaching to organise and conduct webinars as a means of developing foreign-languages-for-specific-purposescompetence]. XI Mezhdunarodnaja nauchno-prakticheskaja konferencija «World Science: Problems and Innovations» [XI International Scientific and Practical Conference "World Science: Problems and Innovations"]. Penza, MCNS «Nauka i prosveshhenie», 2017: 261-265.

11. Potapchuk O.I. Mobil'nye informacionno-kommunikacionnye tekhnologii obucheniya v professional'noj podgotovke budushchih inzhenerov-pedagogov [Mobile learning information and communication technologies 
to train teaching engineers]. http://sci-article.ru/stat.php?i=1436386051 (accessed June 6, 2017).

12. Sventickij E.I. Vebinary kak innovacionnoe sredstvo obrazovaniya i vospitaniya aktivnoj molodezhi [Webinars as a means of educating top-performing youth and developing their personality]. Obrazovanie i nauka v sovremennyhusloviyah: materialy II mezhdunar. nauch.-prakt. konf. Cheboksary: CNS «Interaktivplyus». 2015 [Education and science in modern conditions: materials II international. scientific-practical. Conf. (Cheboksary, January 15, 2015)]: 221-222.

13. Sidorov S.V. Vebinarkak forma distancionnogo interaktivnogo obucheniya [Webinar as a means of distance interactive learning]. Available at: http://si-sv.com/publ/1/vebinar/14-1-0-351 (accessed June 4, 2017).

14. Terent'eva M.A. Vebinar - seminar novogo pokoleniya v vysshej shkole [Webinar as a seminar of the new generation in the system of higher education]. Problemy $i$ dostizheniya sovremennoj nauki. 2015. № 1 (2), pp. 32-35.

15. Shtulman, E. A. Metodicheski jeksperiment v sisteme metodov issledovaniya [Methodological experiment in the system of research methods], Voronezh, VGU Publ. 1971. 144 p.

16. Sharp G., Hemmings B., Russell K., Murphy B., Elliott S. Academic boredom among students in higher education: A mixed-methods exploration of characteristics, contributors and consequences. Journal of Further and Higher Education. 2016. № 41: 657-677.

17. Bengtsson F., Granmo M. An active partnership: How engaging students as co-producers will change your classroom. The FASEB Journal, 2017. FASEB. http://www.articlesfactory.com/articles/education/webinar-innovative-applications-of-raptivity-in-education.html (accessed February 19, 2018).

18. Elsayed Y.E., La Lopa M. Active and Interactive Teaching Methods: A Study of Their Use in Hospitality Higher Education. Available at: http:// www.academia.edu/27721291/Active_and_Interactive_Teaching_Methods_A_Study_of_Their_Use_in_Hospitality_Higher_Education.

19. Schmidt P., Pittner Ja. Smart off-line webinar for distant education. Otkrytoe obrazovanie. 2013. № 5: 64-66. 


\section{ДАННЫЕ ОБ АВТОРАХ}

Неволина Ксения Викторовна, кандидат филологических наук Иркутский государственный университет путей сообщения ул. Чернышевского, 15, г. Иркутск, 664074, Российская Федерация

knevolina@mail.ru

Подкаменная Елизавета Васильевна, кандидат педагогических наук

Иркутский государственный университет

ул. Карла Маркса, 1, г. Иркутск, 664033, Российская Федераџия baks-3000@mail.ru

Фетисова Светлана Анатольевна, кандидат филологических наук Иркутский национальный исследовательский технический университет

ул. Лермонтова, 83, г. Иркутск, 664074, Российская Федерациия s_fetisova@mail.ru

\section{DATA ABOUT THE AUTHORS}

Nevolina Ksenia Viktorovna, Candidate of Philology

Irkutsk State Transport University

15, Chernyshevsky Str., Irkutsk, 664074, Russian Federation knevolina@mail.ru

Podkamennaya Elizaveta Vasilievna, Candidate of Pedagogical Sciences Irkutsk State University

1, Karl Marx Str., Irkutsk, 664033, Russian Federation baks-3000@mail.ru

Fetisova Svetlana Anatolievna, Candidate of Philology

Irkutsk National Research Technical University 83, Lermontov Str., Irkutsk, 664074, Russian Federation s_fetisova@mail.ru 